\title{
Complications of acute pancreatitis in tertiary care hospital
}

\author{
Soubia Akhter, Zaeem UR Rehman Khan, Bilal Ahmed, Farah Ahmed, \\ Zahid Ali Memon
}

\begin{abstract}
Aims: The aim of this study was to determine the complications of acute pancreatitis in tertiary care hospital. Methods: Hundred patients diagnosed with acute pancreatitis were analyzed in this prospective cohort study from July 2015 to July 2016. Complications were studied. Cholelithiasis was found to be the most common cause of acute pancreatitis in our setting. Results: Acute pancreatitis is defined as reversible inflammation of pancreatic parenchyma which is characterized by the presence of interstitial edema, acute inflammatory cell infiltrate and varying degree of cellular apoptosis, necrosis and hemorrhage. Cholelithiasis and alcohol were found to be the most common causes of acute pancreatitis. Alcohol, Smoking, some medications are the major risk factors. The major complications of acute pancreatitis are pseudocyst, pleural effusion, sepsis, shock or internal bleeding, fluid collection, ascites. Conclusion: Acute pancreatitis is one of the most common gastrointestinal ailments with high morbidity and mortality worldwide and at our set up too. Like any other disease occurrence of complications may worsen the prognosis of acute pancreatitis. Acute fluid collection around pancreas came out to be the common complication.
\end{abstract}

Soubia Akhter ${ }^{1}$, Zaeem UR Rehman Khan ${ }^{1}$, Bilal Ahmed ${ }^{1}$, Farah Ahmed ${ }^{1}$, Zahid Ali Memon ${ }^{1}$

Affiliation: ${ }^{1}$ Dow University of health and sciences, Karachi, Pakistan.

Corresponding Author: Farah Ahmed, Dow University of health and sciences, Karachi 74200, Pakistan; Email: farahahmed153@gmail.com

Received: 07 January 2017

Accepted: 29 April 2017

Published: 04 July 2017
Keywords: Acute disease, Acute pancreatitis, Amylase, Alcohol cholelithiasis, Inflammation

\section{How to cite this article}

Akhter S, UR Rehman Khan Z, Ahmed B, Ahmed F, Memon ZA. Complications of acute pancreatitis in tertiary care hospital. Int $\mathrm{J}$ Hepatobiliary Pancreat Dis 2017;7:23-27.

Article ID: 100069IJHPDSA2017

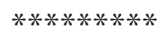

doi:10.5348/ijhpd-2017-69-OA-5

\section{INTRODUCTION}

Acute pancreatitis is defined as reversible inflammation of pancreatic parenchyma which is characterized by the presence of interstitial edema, acute inflammatory cell infiltrate and varying degree of cellular apoptosis, necrosis and hemorrhage. Acute pancreatitis is one of the most common gastrointestinal cause of death with mortality around $5 \%$ while $47 \%$ in patients with multiple organ failure [1]. It can be divided into the following categories: edematous and interstitial or mild acute pancreatitis; necrotizing or severe acute pancreatitis. Severe acute pancreatitis is a multisystem disease which is characterized by two phases the first phase comprises multiple organ system failure due to a systemic inflammatory response and second phase associated with complications such as necrosis, pseudocysts, pleural effusion or ascites [2].

Worldwide the annual incidence of acute pancreatitis varies, with western world reporting an increased occurrence over the last 40 years [3]. The two most common causes of acute pancreatitis are gallstones and 
alcoholism. Both of them account for $80 \%$ cases of acute pancreatitis. The other important causes are abdominal trauma, hyperlipidemia, hypercalcemia and viral infections [4]. According to a research, some medications also play a role in inducing acute pancreatitis which are classified in four different classes [5]. Smoking is also considered as a cause of acute pancreatitis depending on the age, sex, body mass index and alcohol consumption [6]. In approximately, $20 \%$ of the cases etiology remains unknown [7]. Other less common etiologies of acute pancreatitis are sphincter of Oddi dysfunction and pancreas divisum.

In a research performed in Europe on incidence and mortality due to acute pancreatitis, it was found that the incidence of acute pancreatitis is increased from 12.415.9 per 100,000 person annually, however the death toll remain stable with 1.5 per 100,000 person annually with the risk of incidence and mortality increases with age [8]. The incidence of acute pancreatitis in our country is still not known. A 100\% increase in overall hospitalization of patients with acute pancreatitis in the US is noted during last two decades [9]. Similarly, an increase of $75 \%$ is noted in The Netherlands between 1992 and 2004 with further increase of $9.9 \%$ in 2010 [10]. The incidence of acute pancreatitis is more in women under 35 years $(11 \%$ per year) and in male aged 35-45 (5.6\%), in England [11]. In our study, we found it being more common in participants aged between 20-30 years. Along with it the complications were also common in the same age group, probably because of the fact of high incidence in the young age group.

Complications of acute pancreatitis are long lasting shock or massive internal bleeding, renal problems, hepatic failure, intra-abdominal suppuration, abscess, peritonitis, sepsis, pseudocyst, biliary stasis, bile flow obstruction associated with jaundice, death due to pancreatitis is largely associated with necrosis of pancreas [12].

The aim of this study was to determine the complications of acute pancreatitis in tertiary care hospital.

\section{MATERIALS AND METHODS}

\section{Patients}

This is one year prospective cohort study which comprises all adult patients hospitalized in tertiary care setup of Pakistan, from July 2015-July 2016, admitted for the treatment of acute pancreatitis.

\section{Inclusion criteria}

Patients suffering from acute episodes of pancreatitis were included. Inclusion criteria were typical upper abdominal pain/epigastric pain which radiated to back in few patients, fever, nausea/vomiting and elevated serum amylase $\left(\mathrm{N}=25^{-100} \mathrm{U} / \mathrm{L}\right)$ and lipase $(\mathrm{N}=\mathrm{O}-160 \mathrm{U} / \mathrm{L})$.

\section{Exclusion criteria}

Young patients of age $<12$ were precluded from the analysis of this research study.

\section{Sample size}

The sample size of this study is 100 patients diagnosed for acute pancreatitis.

\section{Data collection process}

For this study, we made the questionnaire for data collection, we used to go to patient's bed, after taking verbal consent we collect the data by analyzing the hospital file and reports of every patient. The main points of questionnaire were age, gender, hemoglobin, platelets, direct bilirubin, total bilirubin, serum, amylase, ALT, glucose, ultrasound finding, computed tomography scan finding, treatment, and complications.

\section{Data analysis}

The data was analyzed by SPSS version 17.0. Frequencies and percentages of all variables were calculated. Confounders and stratifications were controlled by strict follow of inclusion and exclusion criteria. The results of the study were compared with national and international studies on the similar objectives.

\section{RESULTS}

Out of 100 participants $66 \%$ were females and $34 \%$ were males. The mean age of the patients was 38.1 and standard deviation was 15.3 . The analysis of the data showed acute fluid collection around pancreas being the top line complication with figure of $41 \%$. Followed by other complications including pleural effusion (22\%), pseudocyst (14\%), pancreatic ascites (13\%), while sterile (6\%) and infected (5\%) pancreatic necrosis, portal or splenic vein thrombosis (3\%), hyperglycemia (2\%), hypocalcemia (1\%), renal failure (1\%) are rare. The participants who were aged between 21-30 years came out to be predominant who developed complications. The mortality was $0 \%$.

\section{DISCUSSION}

Our study is designed to compare different complications of acute pancreatitis. This prospective cohort study was conducted in tertiary care hospital Karachi.

Biliary disease and alcohol abuse are leading cause of acute pancreatitis reported in $55-85 \%$ of patients in literature. In France, reported incidence of biliary acute pancreatitis has ranged from 24-46\%, whereas the statistic for alcoholic acute pancreatitis has exhibited 
less variability 33-38\%. Nevertheless, gallstones appear to be the leading cause acute pancreatitis, reported for $38-43 \%$ of patients, whereas alcoholic acute pancreatitis has been found in $31 \%$ of patients [13]. The proportions were slightly different in our series where incidence of cholelithiasis is 33\% in comparison with no known case of alcoholic pancreatitis. According to a research conducted

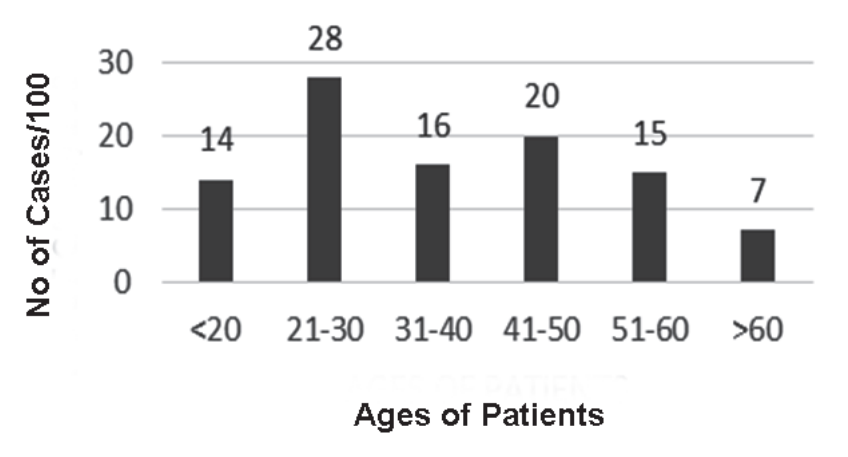

Figure 1: Age groups diagnosed with acute pancreatitis.

Table 1: Frequency of male and female patients having acute pancreatitis

\begin{tabular}{lcccc} 
& Frequency & Percent & $\begin{array}{c}\text { Valid } \\
\text { Percent }\end{array}$ & $\begin{array}{c}\text { Cumulative } \\
\text { Percent }\end{array}$ \\
Female & 66 & 66.0 & 66.0 & 66.0 \\
Male & 34 & 34.0 & 34.0 & 100.0 \\
Total & 100 & 100.0 & 100.0 & \\
\hline
\end{tabular}

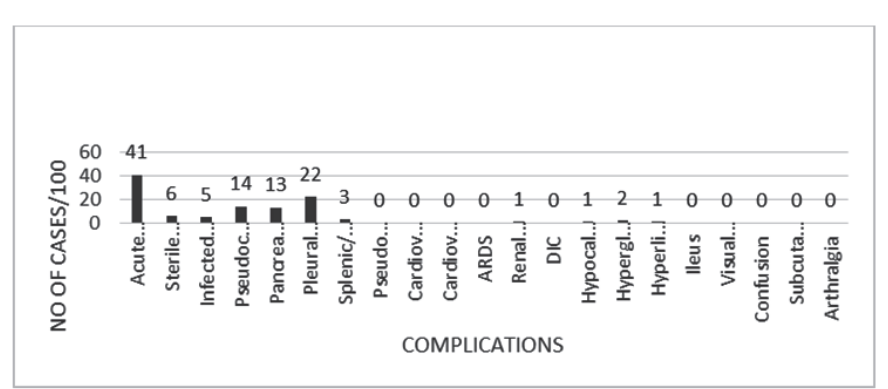

Figure 2: Frequency of complications found in acute pancreatitis.

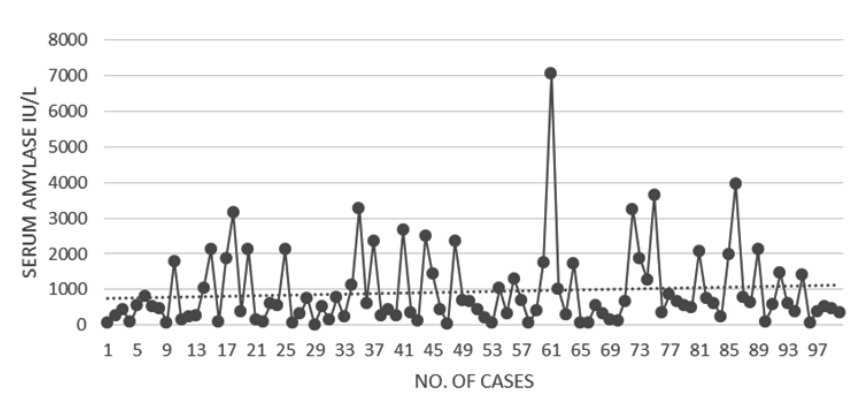

Figure 3: Values of serum amylase in 100 cases of acute pancreatitis. in Paris, biliary acute pancreatitis is mostly present in older people of average age 50-55 years [13]. As we have found in 100 cases, comprising of minimum 14 years to maximum of 70 year, cholelithiasis was predominant in 21-30 year age group (Figures 1 and 2).

The data analysis also showed female to male predominance with the ratio of 2:1. This epidemiological data was also confirmed in other study which stated that biliary acute pancreatitis being twice frequent in women as in men [14].

The most common complication was found to be acute fluid collection. Pancreatic fluid collection is a result of pancreatic wall injury by any cause. In our study, 41 cases of acute fluid collection were found in 100 patients (Table 1). However in a study conducted in the USA, there were 16 patients with 'pancreatic fluid collections' in a group of 32 patients with complicated pancreatitis [15].

Acute pseudocyst formation is a frequent phenomenon in patients during moderately severe episodes of acute pancreatitis [16]. Pseudocyst is a cavity attached to pancreas lined with epithelium. It may contain pancreatic enzymes, blood and pancreatic tissue [17]. In our research, pseudocyst was found in 14 out of 100 cases. In a study, 14.6 cases of pseudocyst were documented in 350 patients [16].

Several pathophysiological mechanisms are involved in the development of inflammatory process that takes place in retroperitoneal area during the early phase of acute pancreatitis leading to pleural effusion. Most pleural effusions are found on left side, but they may also present on only the right lung or both lungs. Pancreas lies just beneath diaphragm, pancreatic swelling may obstruct the lymphatic drainage of upper part of diaphragm. Due to collection of lymph at the base of lung, an effusion forms. Alternatively, acute pancreatitis also damage pancreatic ducts so it may result in leakage of pancreatic enzymes into the surrounding tissues. If the enzymes pass through the diaphragm, they can damage lungs and forms pleural effusion. We observed 22 cases in 100 patients, but in a study in USA, 4-17\% of cases were isolated [18].

Fourth leading complication of acute pancreatitis in our setup is pancreatic ascites. It is the persistent accumulation of large amounts of intraperitoneal fluid, due pancreatitis which is associated with high amylase level (i.e., > $200 \mathrm{IU} / \mathrm{dl}$ ). Analysis of lab investigating serum amylase in one hundred patients showed a trend line at slightly below $1000 \mathrm{IU} / \mathrm{L}$ on average, and above $1000 \mathrm{IU} / \mathrm{L}$ in 30 cases approximately (Figure 3 ). Mostly the nature of ascitic fluid is serous but sometimes it may be turbid, serosanguinous or chylous [19]. In our study, 13 cases were diagnosed in 100 patients (Table 1 ), however in another study where one hundred patients with a diagnosis of acute pancreatitis were investigated. Ascites was found in 18 patients, pleural effusion in 20 and pericardial effusion in 17 patients [19]. 


\section{CONCLUSION}

Acute pancreatitis is one of the most common gastrointestinal ailments with high rates of morbidity and mortality rate worldwide and at our set up too. Like any other disease occurrence of complications may worsen the prognosis of acute pancreatitis. Acute fluid collection around pancreas came out to be the most common complication. No study from our country ever conducted on complications of acute pancreatitis. This study will contribute in the medical literature as the enrichment of this specific topic. We recommend more works in the same stream.

$* * * * * * * * *$

\section{Author Contributions}

Soubia Akhter - Substantial contributions to conception and design, Acquisition of data, Analysis and interpretation of data, Drafting the article, Revising it critically for important intellectual content, Final approval of the version to be published

Zaeem UR Rehman Khan - Substantial contributions to conception and design, Acquisition of data, Analysis and interpretation of data, Drafting the article, Revising it critically for important intellectual content, Final approval of the version to be published

Bilal Ahmed - Substantial contributions to conception and design, Acquisition of data, Analysis and interpretation of data, Drafting the article, Revising it critically for important intellectual content, Final approval of the version to be published

Farah Ahmed - Substantial contributions to conception and design, Acquisition of data, Analysis and interpretation of data, Drafting the article, Revising it critically for important intellectual content, Final approval of the version to be published

Zahid Ali Memon - Substantial contributions to conception and design, Acquisition of data, Analysis and interpretation of data, Drafting the article, Revising it critically for important intellectual content, Group 3Final approval of the version to be published

\section{Guarantor}

The corresponding author is the guarantor of submission.

\section{Conflict of Interest}

Authors declare no conflict of interest.

\section{Copyright}

(C) 2017 Sobia Akhter et al. This article is distributed under the terms of Creative Commons Attribution License which permits unrestricted use, distribution and reproduction in any medium provided the original author(s) and original publisher are properly credited. Please see the copyright policy on the journal website for more information.

\section{REFERENCES}

1. Banks PA, Freeman ML. Practice guidelines in acute pancreatitis. Am J Gastroenterol 2006 Oct;101(10):2379-400.

2. Kingsnorth A, O'Reilly D. Acute pancreatitis. BMJ 2006 May 6;332(7549):1072-6.

3. Zakri RH. Acute pancreatitis: Recent advances in diagnosis and management. Ann Pak Inst Med Sci 2006;2(4):215-7.

4. Asifi M, Choudary MS, Ghazanfar A. Aetiological factors of acute pancreatitis. Ann King Edward Med Uni 2003;9(1):37-9.

5. Badalov N, Baradarian R, Iswara K, Li J, Steinberg W, Tenner S. Drug-induced acute pancreatitis: An evidence-based review. Clin Gastroenterol Hepatol 2007 Jun;5(6):648-61.

6. Lindkvist B, Appelros S, Manjer J, Berglund G, Borgstrom A. A prospective cohort study of smoking in acute pancreatitis. Pancreatology 2008;8(1):6370.

7. Whitcomb DC. Clinical practice: Acute pancreatitis. N Engl J Med 2006 May 18;354(20):2142-50.

8. Eland IA, Sturkenboom MJ, Wilson JH, Stricker BH. Incidence and mortality of acute pancreatitis between 1985 and 1995. Scand J Gastroenterol 2000 Oct;35(10):1110-6.

9. Lowenfels AB, Maisonneuve $\mathrm{P}$, Sullivan $\mathrm{T}$. The changing character of acute pancreatitis: Epidemiology, etiology, and prognosis. Curr Gastroenterol Rep 2009 Apr;11(2):97-103.

10. Spanier BW, Dijkgraaf MG, Bruno MJ. Trends and forecasts of hospital admissions for acute and chronic pancreatitis in the Netherlands. Eur J Gastroenterol Hepatol 2008 Jul;20(7):653-8.

11. Roberts SE, Williams JG, Meddings D, Goldacre MJ. Incidence and case fatality for acute pancreatitis in England: Geographical variation, social deprivation, alcohol consumption and aetiology: A record linkage study. Aliment Pharmacol Ther 2008 Oct 1;28(7):931-41.

12. Kyosola K, Fock G. Complications in acute pancreatitis. Ann Chir Gynaecol Suppl 1976;65(1):7-12.

13. Mennecier D, Pons F, Arvers $\mathrm{P}$, et al. Incidence and severity of non alcoholic and non biliary pancreatitis in a gastroenterology department. Gastroenterol Clin Biol 2007 Aug-Sep;31(8-9 Pt 1):664-7.

14. Ranson JH, Rifkind KM, Roses DF, Fink SD, Eng K, Spencer FC. Prognostic signs and the role of operative management in acute pancreatitis. Surg Gynecol Obstet 1974 Jul;139(1):69-81.

15. Siegelman SS, Copeland BE, Saba GP, Cameron JL, Sanders RC, Zerhouni EA. CT of fluid collections associated with pancreatitis. AJR Am J Roentgenol 1980 Jun;134(6):1121-32.

16. Kim KO, Kim TN. Acute pancreatic pseudocyst: Incidence, risk factors, and clinical outcomes. Pancreas 2012 May;41(4):577-81.

17. Breslin N, Wallace MB. Diagnosis and fine needle aspiration of pancreatic pseudocysts: The role of endoscopic ultrasound. Gastrointest Endosc Clin N Am 2002 Oct;12(4):781-90, viii. 
19. Maringhini A, Ciambra M, Patti R, et al. Ascites, pleural, and pericardial effusions in acute pancreatitis: A prospective study of incidence, natural history, and prognostic role. Dig Dis Sci 1996 May;41(5):848-52.
Access full text article on other devices

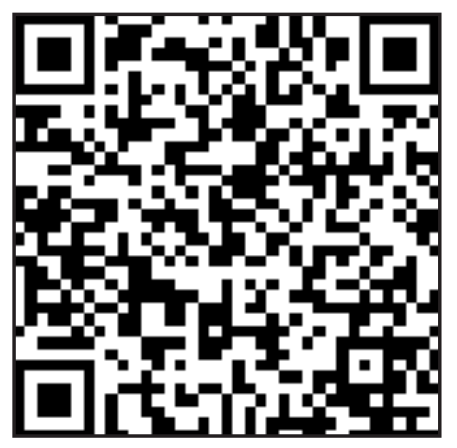

Access PDF of article on other devices

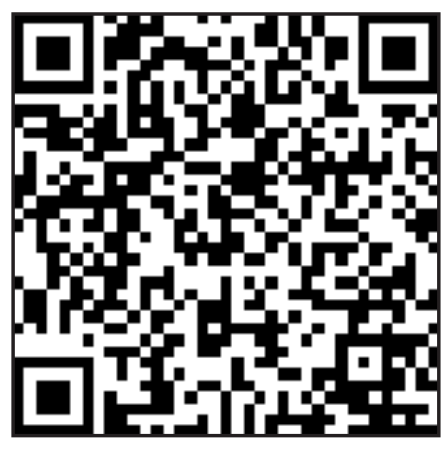

